\section{TELEVISIÓN EN INTERNET}

\section{Carmen Rodríguez Fuentes Profesor Contratado Doctor}

Facultad de Ciencias de la Comunicación. Universidad de Málaga. Avda. Cervantes, 2 - 29071 Málaga (España). Email: rguezf@uma.es

\section{Resumen}

La televisión, medio de comunicación de masas por excelencia, es parte de ese equilibrador entre la libertad del individuo y la igualdad de todos.

La televisión ha ido evolucionando hasta el punto de que algunos autores aseguran que se ha producido su fallecimiento. Sin embargo, con la expansión de las nuevas tecnologías digitales, la televisión está más viva que nunca. Sus contenidos son los mismos que invaden Internet, las Instituciones siguen su misma onda, y aún es más, la televisión tiene una nueva forma de interactuar con el usuario, estamos hablando de la "sociedad de la ubicuidad".

\section{Palabras clave}

Creación Internet, televisión, interactividad, televisión interactiva, prosumer

Key Words

Internet, television, interactivity, interactive television, prosumer

\section{Abstract}

Television, as a wide-spread mass media, plays its role as a balance between an individual's liberty and everyone's equal rights.

Many experts think Television has reached its rock bottom and is finally dead. However, some others think it's more than ever alive, due to the expansion of new digital technologies. Its contents are the same as those found in the Internet. Institutions also share their contents with Internet. Television interacts in a new way with the individual, this is "The Ubiquitous Society". 


\section{Introducción}

La televisión construye, cautivando a una gran audiencia, un discurso pedagógico que termina por no interpelar a nadie.

Aprender a ver los medios es algo muy distinto a aprender a ver el sentido de un texto. La concepción de la comunicación nos ayuda a entender los medios audiovisuales. Definir la comunicación supone analizar las relaciones entre el sistema técnico, el modelo cultural y la organización económica y jurídica del conjunto de las técnicas comunicativas de una sociedad.

Algunos autores apoyan la ideología técni$\mathrm{ca}$, que se apoya en que una revolución tecnológica provocará la creación de nuevas sociedades. Algunos anticipan que Internet está en camino de conseguirlo.

No es descabellado pensar que la tecnología de la comunicación pueda influir tanto en nuestra sociedad, ya que, en las sociedades democráticas occidentales, la comunicación se encuentra al mismo nivel que la libertad y la igualdad de los ciudadanos.

La fuerza de los medios de comunicación generalistas consiste precisamente en englobar los dos extremos de la comunicación, la escala individual y la colectiva, mientras que los nuevos medios se sitúan principalmente en la esfera individual.

La televisión nunca ha gozado de mucha legitimidad cultural ni intelectual, aunque siempre ha estado ahí.

Los medios tradicionales - prensa, radio y televisión- definen sus estrategias a partir de la oferta, mientras que los nuevos medios de comunicación se basan en la demanda.

Hay tres palabras fundamentales para entender el éxito de las nuevas técnicas: autonomía, dominio y velocidad. Todos podemos actuar sin intermediarios: actúo y el resultado es inmediato.

\section{Objetivos}

El presente artículo tiene como objetivos:

- Reflexionar sobre el estado actual de la televisión, entendiéndolo como una consecuencia de la evolución que ha sufrido la televisión desde sus orígenes hasta la actualidad.
- Conocer el sistema de comunicación que se está consolidando a partir de la expansión de las tecnologías digitales.

- Estudiar los diferentes modelos televisivos.

- Comprobar que, aún hoy, las Instituciones siguen en la línea tradicional de utilizar la televisión como el mejor me- 
dio para llegar a un mayor número de telespectadores. La cultura figura como la sección más protegida.

\section{Metodología}

En este texto analizamos el estado actual de la televisión, la aparición de nuevos conceptos que participan en el sistema de comunicación que ha nacido con el siglo XXI.
Para realizar el trabajo hemos estudiado el website de las televisiones principales que se dan cita en Internet. También hemos consultado y revisado la bibliografía que existe sobre este tema.

\section{La televisión, medio de comunicación de masas por excelencia}

La televisión, el mayor antagonista de la letra, es algo que se contempla sin esfuerzo, sirve para contactar con una sola mirada con el exterior.

La televisión es un medio de comunicación de masas, y para poder ser definido como tal, debe de cumplir unas características, como la periodicidad y otras. Aunque una sociedad sea capaz de crear cultura, no quiere decir que facilite la creación de medios de comunicación de masas. Por ejemplo, como asegura el profesor Aguilera, los griegos, a pesar de construir una sociedad culturalmente muy avanzada, y con infinidad de géneros comunicativos, no introdujeron el factor "periodicidad" en sus géneros, por lo que no podemos apreciar con claridad la existencia de medios de comunicación.

"Su correspondencia y su recepción de noticias no son rítmicas, no son periódicas, $y$ quizá sólo en eso, en un futuro, todavía remoto, la cultura europea va a generar una forma nueva de comunicación, además de la técnica última que se convierte en un micromundo, donde a su vez los géneros griegos se repiten” (Aguilera, 1988. pág. 140).

En cambio, los romanos sí crearon una auténtica sociedad comunicativa, donde no sólo se produce comunicación en las ciudades -como ocurría en Grecia-, sino que se establece un auténtico entramado de información en todo el imperio -probablemente este sea el primer antecedente organizado de lo que hoy entendemos por redes de comunicación-.

Posteriormente, durante la Edad Media se produce una vuelta atrás, los medios de comunicación no avanzan, y tan solo se desarrollan los libros escritos a mano. La comunicación es prácticamente oral, lo que desencadena una parálisis en el desarrollo 
intelectual. Con el descubrimiento de la imprenta se produce una revolución comunicativa, dejando atrás los sistemas de comunicación, mucho más cerrados y desarrollados anteriormente.

La implantación y desarrollo de la imprenta traerá consigo el espíritu renacentista, surgiendo lo que algunos han venido en llamar "la explosión de la comunicación", o "la cultura de la imprenta" o "la Galaxia Gutenberg”.

El renacimiento es una vuelta hacia las culturas clásicas; dicho movimiento se desarrolla en un marco histórico y social, que facilita la integración de la imprenta en los modos de producción de cultura. Existía una verdadera demanda de conocimiento de todas las materias en general, y la imprenta es el invento técnico que facilita generalizar la cultura al abaratar las técnicas de producción.

Por último, señalar que en este periodo existía una demanda social de libros que no podían satisfacer los copistas artesanos (Breton y Proulx, 1990. Págs 38-47).

A partir del siglo XVI y hasta el siglo XIX, etapa que se identifica con el absolutismo y las revoluciones sociales, se produce un importante avance del pensamiento, que desemboca en la sociedad industrial. En este periodo, filósofos como Hobbes, Rousseau, Montesquieu o Adam Smith sentarán las bases de nuestro actual sistema político y económico. Sin embargo, durante tres siglos, el elemento técnico utilizado para comunicar se basa en el principio de la imprenta.

Durante el siglo XIX se producirán cambios comparables con lo que supuso la invención de la imprenta. La sociedad capitalista, tras el desarrollo industrial, busca y facilita una sociedad de servicios donde el entretenimiento y el ocio tienen mucho que decir. La sociedad es definida por otros factores, así aparecen nuevos conceptos como "sociedad de masas" (Giner, 1972). La sociedad de masas se reconoce, según Monzón, por las siguientes características:

"Expansión del capitalismo, proceso de industrialización, fuerte crecimiento demográfico y urbano, tendencia al igualitarismo, fortalecimiento del Estado, nuevas clases medias y aparición de medios de comunicación masivos” (Monzón, 1987).

La sociedad de masas genera su propia cultura, fruto de la clara influencia de los medios de comunicación. Umberto Eco, en su libro Apocalípticos e integrados, habla de distintas posiciones frente a esta cultura de masas: la aceptación o no de esta nueva concepción de la cultura, coloca a distintos estudiosos y pensadores en diferentes frentes, los que la apoyan -integrados-, los que la rechazan -apocalípticos-, así como un tercer grupo calificado como "Crítico" (Moragas, 1981, pág. 7).

Para los apocalípticos, cuyo máximo representante es el sociólogo norteamericano Mc Donald, la cultura de masas provoca en 
la comunidad una tendencia al discurso uniforme, que pasa por: destrucción de valores propios de cada grupo étnico, homogeneización de los receptores, y sometimiento a la ley de oferta y demanda. Por el contrario, los defensores de la cultura de masas consideran que ésta consigue, entre otras cosas, que el ciudadano participe en igualdad de derechos de la vida pública y se generalice el acceso de la cultura.

Para Moragas, los críticos realizan un análisis de la sociedad desde perspectivas más amplias, y con una interpretación marxista de los problemas. Los integrantes de la Escuela de Frankfurt buscan la raíz política de los problemas comunicativos (Eco, 1968, pág. 73).

Sin embargo, con independencia de una $u$ otra corriente, observamos cómo el factor tecnológico que origina los nuevos medios de comunicación de este siglo -radio, televisión, autopistas de la información- condiciona el desarrollo social y cultural.

Según este investigador, nos encontramos ante una sociedad que ha prestado especial atención a los servicios sociales -educación, sanidad, seguridad social- y a los servicios profesionales -informática, tecnología, comunicaciones-. Pero los condicionantes de la sociedad capitalista han llevado a un mayor desarrollo del segundo grupo de servicios en detrimento del primero. La comunicación y las nuevas tecnologías han conseguido adelantarse al progreso de las garantías sociales del individuo (Bell, 1993).

Así pues, podemos asegurar que, en la actual sociedad, hemos asistido a un proceso de pérdida de los valores propios de las pequeñas comunidades. Una desaparición que ha sido propiciada por el desarrollo de las nuevas tecnologías de la comunicación, que, al tiempo que han democratizado el uso y acceso a estos medios, también han creado un discurso dominante.

Una forma de comunicación, que lejos de respectar los rasgos y culturas autóctonas de los pueblos, ha servido para uniformizar a una gran cantidad de pueblos bajo el techo de una misma cultura.

La comunicación es el núcleo de la modernidad; en nuestras sociedades democráticas es necesaria la intervención de los medios de comunicación para equilibrar la libertad individual y la igualdad colectiva. Estas dos características poseen sentidos contradictorios propios de nuestra democracia, ya que en estas sociedades se reconoce el derecho a la libertad de información y de comunicación, por ser la base de las relaciones sociales.

La televisión, como medio de comunicación de masas, es parte de ese equilibrador entre la libertad del individuo y la igualdad de todos. Pero, uno de los aspectos que la hacen más singular de entre los distintos medios de comunicación, es la capacidad que tiene la televisión de crear una realidad virtual en mutación permanente. Las imá- 
genes funcionan solas, y entre medias de ellas se encuentra el espectador, seducido para, posteriormente, ser convencido $\mathrm{y}$ controlado.

Por primera vez, durante el siglo $\mathrm{XX}, \mathrm{y}$ con la instalación de la televisión en el mundo entero, la realidad ha sido coconstruida por la televisión. La televisión nos ha enseñado que lo que aparece en su pantalla es real, precisamente porque aparece en la pantalla, y nos ha enseñado modelos de vida, como el estadounidense, y lo hemos deseado por que eran reales y existían gracias a la televisión. Como ejemplo de ello, podemos señalar cómo muchos testigos del atentado de las Torres Gemelas corrían a ver la televisión, para comprobar que aquello que habían visto era cierto.
Como dice Marcuse, “... la tecnología es un proyecto histórico-social en el que se proyecta lo que una sociedad se propone hacer con los hombres y con las cosas...”. La tecnología visualiza lo que una sociedad es, a un nivel concreto, y también a un nivel metafórico.

Los diferentes medios de comunicación vehiculan la cultura postmoderna. Pero hay uno que destaca por ser el que marca las pautas a los otros: se trata de la televisión.

Aunque Internet empieza a expandir sus códigos a los otros medios, la televisión es el más consumido y el más importante a escala mundial.

\section{Nuevas concepciones de la televisión}

Los primeros experimentos de televisión interactiva (TVi) se llevan a cabo en Norteamérica y Japón a partir de 1977, le seguirán otras experiencias en Europa. Entre las más destacadas figuran las de Time Warner en Columbus (Ohio), y el proyecto japonés Hi-OVIS.

En 1976 se llevó a cabo un experimento en tres comunidades de la localidad de Reading (Pennsylvania, EEUU). Entre ellos se estableció una red de vídeo de doble dirección, con el objetivo de ofrecer información y programas educativos para ciudadanos de la tercera edad. El experimento demostró ser muy eficaz para las relaciones entre las instituciones públicas y los ciudadanos.

En Europa, el desarrollo tecnológico ha facilitado el aumento de usuarios en servicios interactivos. El Multimedia Home Platform (MHP) es un estándar europeo, un sintonizador con MHP no es mucho más caro que uno que no lo lleve, con la ventaja de que siempre será más barato que un ordenador. No sólo un televisor es más barato que un PC, sino que tiene la ventaja de que el consumidor habitual del audiovisual está más familiarizado con un televi- 
sor, y además, es más fácil de utilizar para cualquier usuario que un PC.

A pesar de lo dicho, la aceptación de la TVi es un proceso lento. Siguiendo el análisis de Brow (2001), éste plantea varios factores que limitan la demanda de la TVi; la primera y principal es aquella que señala como más preocupante, y es la existencia de rezagados -telespectadores que desean una televisión tradicional y gratuita, sin innovaciones interactivas-. Por otro lado, tenemos telespectadores que, aun aceptando la TVi, rechazan sus limitaciones cambio periódico de descodificadores y servicios peores que los de Internet-, y por último, la preocupación por la seguridad los usuarios temen que sus datos privados puedan estar a merced de cualquiera-.

Los recelos referidos por parte de los usuarios no han frenado la tendencia tecnológico-jurídica que nos obliga a que todos los aparatos de televisión del mundo sean sustituidos. La Unión Internacional de Telecomunicaciones anunció en 1997 en Ginebra, la necesidad de deshacerse de todos los aparatos de televisión, pues quedaban obsoletos frente a las nuevas tecnologías digitales. De aquí a unos años, ya no existirán aparatos analógicos de televisión. En su lugar, el mundo digital nos ofrece una fidelidad de imagen muy similar a la imagen cinematográfica de $35 \mathrm{~mm}$, y con una extraordinaria calidad de sonido distribuida en 16 canales.

En España, la digitalización total se completará en el año 2010.
El desarrollo de la TVi trae consigo una nueva concepción de televisión. Anteriormente, la televisión resultaba ser un medio de comunicación unilateral; sin embargo, ahora con la TVi, al telespectador se le ofrece el acceso a Internet a través del televisor, intercambio de programas, información a través de vía satélite. En suma, una variedad de servicios que obliga a plantearse el mismo concepto de televisión.

Las diferentes experiencias de la TVi muestran que, el hecho de que el usuario pueda tomar la iniciativa de comunicarse con otros, hacen a la TVi muy atractiva para el usuario. Si bien esto no es suficiente, se demandan por parte del usuario servicios interactivos con una amplia gama de ofertas.

En los últimos años, en la televisión europea se ha producido un cambio que ha sido el paso de una televisión de servicio público a otra concurrencial. Al mismo tiempo, el número de usuarios interesados en la TVi crece a un ritmo moderado, porque Internet ya les ha preparado para un cierto nivel de interactividad -en la televisión interactiva uno mismo tiene el control-.

En la actualidad, los servicios que ofrece la televisión interactiva prácticamente son una versión modificada de contenidos o programas ya existentes. Sería un error que este tipo de televisión se limitase a reproducir lo que ya nos ofrece la televisión convencional, o lo que encontramos en Internet, sencillamente porque ya existen esos servicios. Por el contrario, la televi- 
sión interactiva puede invertir en la producción de contenidos de gran calidad, aprovechar la interactividad de forma más innovadora y, por último, dar espacio a las marcas consolidadas en los canales convencionales.

Para algunos estudiosos, la televisión clásica ha muerto, y ello nos obliga a adentrarnos en un nuevo terreno televisivo, donde la virtualidad prima sobre la realidad, por ser la metáfora de la posmodernidad. Será una nueva forma de “... sustituir lo vivido por lo simulado, y lo experimentable por su programación...”.

Resulta difícil evaluar el futuro creativo de la televisión. En Europa, desde los años noventa, se ha instalado la lógica comercial, por lo que el principal objetivo es obtener un continuo aumento de sus audiencias. Incluso las televisiones públicas han caído en la misma dinámica, dejando abandonado todo proyecto cultural.

Sin embargo, no hay que perder de vista que se ha creado un nuevo imaginario colectivo, propio de una audiencia que, desde su nacimiento, se han visto rodeados del aparataje tecnológico -vídeos domésticos y ordenadores- novedoso -y a veces extrañopara algunos de sus mayores.

La consecuencia de todo ello es que nos hallamos frente a unos modos de representación audiovisual diferentes a la televisión convencional. Los jóvenes han desarrollado un nuevo lenguaje que se sustenta en las más recientes tecnologías, y la televisión interactiva tiene la oportunidad de tomar el relevo.

El gran desarrollo de redes interactivas multimedia que se está dando a nivel mundial provoca cambios económicos y culturales. Aún no podemos prever lo que supondrán a largo plazo. Lo que sí podemos afirmar es que aquellos programas que no resultan rentables desaparecen, y que la oferta que se ofrece es tan amplia que podemos recibir canales de países distintos a los nuestros. Además, durante las veinticuatro horas del día existe programación plural.

En definitiva, nos encontramos en la actualidad ante un nuevo modelo comunicativo, que podemos denominar interactivo. Este modelo es singular por el uso que se hace de él, y resulta ser la antítesis del modelo clásico unidireccional. El espectador puede elegir detalles de la trama de una serie televisiva, o acceder a una noticia concreta. La interactividad permite búsquedas y navegación, creación de universos reales o virtuales, acceso a información, compras o entretenimiento.

Todos estos cambios generan una televisión fragmentada. Además, los modos televisivos no sólo se dan en el receptor de televisión sino también en el ordenador, consolas de videojuegos y en los móviles - cuarta pantalla-.

Con todo ello, tendríamos que preguntarnos si no estamos asistiendo al fallecimiento de la televisión, o nos encontramos ante el 
hecho del nacimiento de una nueva televisión -nuevos usos y soportes-.

Algunos autores, como David James, consideran que

“... la actual televisión completa la disolución del arte popular en una cultura de consumo industrial, y completa la colonización del ocio y la industrialización de la mente". (James, 1986).

A finales de 1995 nace la web -la cara gráfica de Internet-. Como ya es bien conocido de todos, el ordenador deja de ser un mero tratamiento de textos para abrirle paso a todas las posibilidades que ofrece el audiovisual, también por Internet. Así, tenemos el caso de Net tv que es una televisión que está conectada por un lado al cable coaxial y, por otro, a Internet, la mayoría de las veces gracias a un cable de teléfono.

El webtv es un proyecto que comenzó tímidamente pero que ya tiene muchos adeptos y probabilidad de éxito.

Concluyendo, actualmente conviven tres modelos televisivos: el tradicional y generalista, el modelo temático enraizado en la interactividad -que ha modificado las programaciones y el uso de los telespectadores-, y el modelo convergente con Internet.

\section{Nuevo campo: Televisión interactiva e Internet}

Curiosamente a finales del siglo XX se producen dos hechos destacables en relación con los usos del audiovisual, por un lado la aparición de medios de comunicación locales - se apoyan en los rasgos de las culturas autóctonas- frente al poder de los "mass media", que tienden a homogeneizar los medios. En la década de los ochenta, la comunicación local consigue amplias audiencias, gracias a que mantiene relaciones más fuertes con éstas que con las de los medios generalistas.

Y por otro lado, los primeros experimentos de TVi propiamente dicha, que se llevan a cabo en Norteamérica, Europa y Japón, con objeto de verificar la utilidad de nuevos sistemas tecnológicos, para grupos heterogéneos de usuarios con fines comerciales.

Al principio, estos sistemas tecnológicos servicios interactivos- no fueron bien recibidos, pero fueron decisivos para el conocimiento del tipo de interactividad que el público demandaba, y sobre los modelos comerciales que podían resultar viables.

Durante la década de los ochenta se sigue experimentando con la TVi. Progresivamente los avances tecnológicos interactivos se habían ido introduciendo en otros equipos

“... tales como el videograbador, el ordenador personal (PC), el CD-ROM y las panta- 
llas de información interactiva en lugares públicos...”(Jensen 1999, pág. 28).

Se experimenta con el videotexto y el teletexto, que permite únicamente transmitir información escrita y gráficos hasta las pantallas del televisor.

La presencia de los sistemas interactivos cambia la percepción del mundo en la era digital. La interactividad es reconocida en el mundo artístico y nace un arte interactivo, que explora el comportamiento de los cuerpos humanos y el de los sistemas artificiales. Este arte es clara consecuencia de su tiempo. Tiene un objetivo fundamental, que es el de provocar el diálogo entre los sistemas naturales y artificiales, usando las tecnologías para aportar su dimensión estética. En el contexto del ciberarte, el sujeto interface modifica radicalmente la situación del que observa una pintura, una fotografía, un filme, o un vídeo.

En el nuevo entorno digital, la distribución de contenidos televisivos supera con creces la oferta de los canales analógicos. La convergencia tecnológica, la entrada de nuevas empresas, como las operadoras de telecomunicaciones, y las distintas posibilidades de negocio y distribución conforman un mercado muy competitivo y con mucho futuro.

La interactividad se asocia con elementos como las acciones multilaterales, el espacio y el tiempo sincronizados, la simetría en el canal de retorno, el control de la acción y el entendimiento de las decisiones y accio- nes por parte del usuario (Jensen 1998, González Berbés 1999).

Los canales de televisión, tanto en España como en todo el mundo, están muy interesados en las ventajas de la interactividad.

La TVi representa una poderosa evolución en términos de las prestaciones del medio televisivo, porque combina la intensa experiencia del vídeo con la capacidad de realizar transacciones e interactuar, características propias de Internet.

El modelo de comunicación de la TVi es bidireccional, personalizado, y permite satisfacer nuevas necesidades de entretenimiento, comunicación, transacción e información, porque los usuarios estaban demandando contenidos de gran calidad, y estarían dispuestos a pagar por contenidos únicos y personalizados.

En esencia, la TVi supone el desarrollo de la televisión con tecnologías que incluyen un canal de retorno, que posibilitan nuevos usos -acceso a Internet, descarga de contenidos audiovisuales, posibilidad de almacenamiento e intercambio, etc.- por parte del telespectador. La TVi utiliza una combinación de diversas tecnologías que modifican el esquema de la televisión como medio de comunicación unilateral.

Cuando la tecnología lo ha permitido, se ha buscado la interacción entre el telespectador y la señal de televisión. Los primeros síntomas eran el facilitar que el telespectador tuviera acceso al ajuste de parámetros 
de la señal recibida, le siguió el mando a distancia, teletexto, receptor digital, etc.

A comienzos de la década de los noventa, la interactividad técnicamente comenzaba a ser viable, aunque a los consumidores parecía no interesarles demasiado. A finales de la década, la situación había cambiado de forma clara, ya que buena parte de las cadenas digitales ofrecían servicios interactivos implantados comercialmente (Swedlow 2000).

A finales de los noventa Bustamante y Álvarez Monzoncillo (1999) señalaban que los proveedores de TVi irían introduciendo gradualmente nuevos elementos en los programas convencionales, porque los usuarios tardan en acostumbrarse y el desarrollo tecnológico también necesita tiempo.

En estos mismos años se consolida la interactividad como parte sustancial del nuevo modelo comunicativo, gracias todo ello al nacimiento y desarrollo de Internet, y a la expansión de los canales por satélite primero analógicos, luego digitales-. También, la tecnología digital se asienta en todas las fases de la producción del audiovisual, desde la creación hasta la transmisión de la señal.

En la actualidad, la implantación de la televisión digital provoca que se consolide el concepto de multicanal. La no linealidad significa que el espectador ya no está restringido por los horarios y parrillas de programación de las cadenas. Gracias a la digitalización y al boom de Internet, el público puede acceder a los contenidos de las cadenas en el momento que mejor le convenga. No obstante, el usuario necesita un aprendizaje progresivo de las posibilidades de interacción en la TVi.

Hoy en día, una vez consolidados los canales de televisión de pago en la mayoría de los mercados, las principales plataformas de contenidos, sean estos canales, plataformas digitales, redes de cable o televisión digital terrestre, han fijado su atención en los servicios interactivos como un servicio de valor añadido para sus abonados $\mathrm{y}$, por supuesto, como un atributo del futuro negocio comercial. Así, la televisión vía satélite digital se configura como la mejor opción para aplicar sistemas avanzados, en muchos casos interactivos.

El usuario de la TVi desarrolla un papel activo y accede a los programas que le interesan. Ahora puede conseguir más información, con mayor profundidad, junto a nuevas formas de entretenimiento. Sin embargo, Sewart (1999, pág. 255-6) y Toscan (1999, pág. 272-74) planteaban ciertas dudas sobre si el espectador quiere ser activo mientras ve un medio tradicionalmente pasivo como la televisión. Ambos argumentaban que, desde el punto de vista del usuario, la interactividad nunca será muy alta. En cambio, desde el punto de vista tecnológico, sí será cada vez más sofisticada.

La televisión interactiva e Internet son dos sistemas de acceso, de información, ocio y 
gestión, y, aunque desde el punto de vista tecnológico tienen muchas similitudes, son sistemas funcionalmente muy diferentes.

En los dos sistemas, el usuario requiere de un equipo concreto, un ordenador en el caso de Internet, y un receptor digital en el de la TVi. Estos equipos están basados en procesadores potentes, uso de memoria y capacidad de almacenamiento en disco duro. Aunque los usuarios son potencialmente los mismos, el nivel de conocimientos preciso para poner en marcha el ordenador, entrar en Internet, navegar y operar es muy diferente del que precisa un usuario de la televisión interactiva.

La navegación y la interacción son distintas ya que, en un caso, las herramientas son el teclado y el ratón del ordenador, mientras que en la TVi todo se hace con el mando a distancia. En la TVi existen evidentes dificultades para introducir textos. En el caso de Internet, el ratón facilita el desplazamiento por toda la pantalla, y la actuación sobre cualquier punto, permitiendo el teclado introducir textos con gran facilidad. En el caso de la TVi, deben de ser productos de navegación más sencilla, sin necesidad de teclado y que con tres o cuatro acciones del mando pueda llegarse a la opción deseada.

Hace unos años se creía que la TVi desaparecería como tal, pero gracias al renovado impulso de Internet, se está reubicando en el nuevo ecosistema comunicativo.
Internet ha ofrecido un soporte técnico abierto a continuas mejoras, lo que ha propiciado implantar servicios interactivos. De forma paralela, los medios audiovisuales van avanzando en la idea de convergencia con Internet. En este contexto, la interactividad se perfila como uno de los elementos distintivos de la televisión digital.

Sin duda que la complementariedad de medios es un elemento que fomenta la interactividad, y muchas empresas audiovisuales ven en ello un mercado amplio desde donde poder relanzar el sector, aportando otros servicios interactivos muy atractivos para el telespectador.

La preocupación de algunos estudiosos por los efectos de las tecnologías sobre las relaciones sociales humanas, ha dado lugar a una nueva concepción de la comunicación, pasando de una concepción materialista a una ideología técnica de la comunicación. Internet ha supuesto una auténtica revolución; en ello se fundamenta la ideología técnica para afirmar que una revolución tecnológica provocaría una revolución en la estructura global de las sociedades. Porque el arte interactivo interroga la existencia como una posibilidad de reinventar constantemente la vida.

\subsection{Televisión en Internet}

En 1972, en Japón, se creó la tv de alta definición, llamada HDTV (High Definition Televisión) con imágenes superiores a la televisión tradicional. Logrando notables avances imponiéndose en el mercado, por 
encima de Estados Unidos y Europa. Pero a principio de los noventa, con la irrupción de la tv digital, las investigaciones tecnológicas siguieron una vía diferente. La nueva concepción hacía la transmisión de televisión compatible con los PC's. Ahora se necesitaba mayor resolución de imágenes y visibilidad, ya que la pantalla del ordenador se ve a menor distancia que la televisión.

Las nuevas tecnologías digitales abrían el campo para los usos de la televisión, por ejemplo, la integración de la televisión en Internet.

De acuerdo con Paul Levinson, uno de los más destacados intelectuales de la llamada Escuela de Toronto:

"Internet is making content of them all. What began as a medium whose content was text, and expanded in the 1990s to include image and sounds, has become at the turn of the new century a medium that offers telephone (Internet Telephone), radio (Real Audio) and Television (Real video)" (Levison. 1999).

El problema inherente de la naturaleza de Internet estriba en la abundancia de información, lo que hemos dado en llamar "la aguja en un pajar". Ningún ser humano, aunque se dedicase exclusivamente a navegar durante las veinticuatro horas del día, podría acceder a todo lo que le ofrece Internet. De ahí la importancia de la selección, facilitar al usuario herramientas que restrinjan el tiempo necesario para obtener la información concreta deseada.
Internet, en tan solo cuatro años, ha crecido en el número de ordenadores conectados, en usuarios y en contenidos y servicios. El aumento exponencial de usuarios de Internet ha dado lugar a saturación, problemas de gestión, seguridad y legislativos. En términos comparativos, la radio tardó 35 años en conseguir 50 millones de oyentes, la televisión 13, el cable 10 e Internet 3 años.

Existe un aumento exponencial del tiempo dedicado a los medios interactivos. Si se tiene un ordenador en casa, desciende el consumo televisivo, o el tiempo dedicado a leer el periódico. Si se tiene conexión a Internet en el hogar, baja también la escucha radiofónica y discográfica. Con estos cambios de usos, las grandes empresas de los medios de comunicación han decidido proyectarse a través de Internet. Por supuesto que la televisión no ha perdido el tiempo. Las principales cadenas de televisión concibieron la posibilidad de subir a la web su programación ordinaria, por considerar a la televisión en Internet como una simple extensión de la televisión convencional, sin entender que la programación debía ser distinta, ya que no encajaba con el tipo de persona que navegaba por la red.

Pérez de Silva defiende la tesis de que la televisión desaparece con la llegada de la televisión digital. En su libro La televisión ha muerto nos informa de la defunción de la televisión ante los nuevos medios. El satélite e Internet han decidido los nuevos usos 
de la televisión, ahora el espectador elige lo que ve, cuándo, cómo y dónde desea.

Alfin Toffler afirma:

"el medio de comunicación más poderoso y masificador ha sido, evidentemente, la televisión”(Toffler. 1980, pág. 167).

Pero ahora la concepción que se podía tener de la televisión, como el indiscutible medio de masas de la segunda ola antes de los años noventa, tiene que renovarse, y pasa por las conexiones que existen, y pueden existir, entre Internet y la televisión.

Es indiscutible que, con el formidable desarrollo de Internet, la televisión experimenta una decisiva transformación, y el mismo espectador es diferente. El futuro de la televisión -anticipaba Nicholas Negroponte- es la computadora PC. Mientras los medios de difusión convencionales promueven la pasividad dirigida, Internet posibilita la interactividad. La televisión se convierte en contenido de Internet.

El visionario Marshall McLuhan, quien concibió la "sociedad de la información y el conocimiento" como "aldea global", también se anticipó cuando afirmó que los viejos medios se convierten en el contenido de los nuevos medios.

A pesar de todo, aún se puede pensar que cada aparato, el ordenador y la televisión, va a continuar coexistiendo de manera separada.
Nuevos conceptos aparecen en la sociedad comunicativa actual. Alvin Toffler, en su libro La tercera ola, acuñó el término "prosumer" (prosumidor). También Marshall McLuhan y Barrington Nevitt hablan de que, con la tecnología electrónica, el consumidor podría llegar a ser un productor al mismo tiempo.

El presidente de Matsushita Electric Industrial Co. se refiere "a una sociedad en la cual cualquiera puede disfrutar, en cualquier tiempo y lugar, una amplia gama de servicios a través de diversas diapositivas, terminales y roles".

Esta sociedad ha sido bautizada como la “sociedad de la ubicuidad”, cuyo lema es “anyone, anytime, anywhere".

Otro concepto nuevo es el que se refiere a los sujetos que participan de la sociedad de la ubicuidad, son los prosumers. En la sociedad de la ubicuidad no hay emisores y receptores pasivos y separados, que se limiten a consumir los contenidos culturales que ofrecen los medios convencionales, en horarios determinados. En cualquier lugar o momento, el prosumer introduce o consume información que circula en Internet.

Por otra parte, en febrero de 2005, tres programadores que trabajaban para PayPal -Hurley, Chen y Karim- concibieron la posibilidad de abrir un espacio en la red que permitiera almacenar y difundir vídeos a través de Internet: YouTube. En noviem- 
bre de 2006 la revista Time reconoció a YouTube como "invento del año".

Efectivamente, los contenidos de la nueva televisión en Internet los proporcionan los prosumers. El tránsito y la adaptación hacia la nueva televisión por Internet no será fácil para algunas de las grandes cadenas de televisión.

Internet también está cambiando el hábito de ver la televisión, ahora la televisión se adapta a nuestras necesidades particulares.

La televisión en Internet ofrece otras posibilidades fundamentales, primero la gran variedad de información -muchos canales-, y por otro lo más interesante, la naturaleza interactiva que nos permite participar, intercambiar y modificar la información. El espectador medio de la televisión convencional ha pasado a ser creador y consumidor-prosumer-.

La completa integración de televisión e Internet sigue siendo imposible a causa de problemas legales. Y se están buscando soluciones al exceso de información televisiva, proponiendo al telespectador filtros que le permitan reconocer los programas más relevantes para él.

\subsection{Televisión Cervantes, un caso particular de televisión institucional en Internet}

Las democracias occidentales se sustentan en un sistema de valores que se caracteriza por un concreto modelo cultural de rela- ciones individuales y sociales. Son conceptos que admiten distintas perspectivas políticas, filosóficas, etc.-. Nuestro enfoque intentará relacionar los procesos $\mathrm{CO}^{-}$ municativos con el entorno de la realidad social en la que se producen, porque los conceptos de cultura y comunicación nos ayudarán a entender cómo nacen los procesos comunicativos.

El concepto de cultura arranca del Renacimiento y se considera propia de la capacidad humana. La cultura es un proceso muy amplio que se produce en función de la capacidad que tiene el hombre para formar parte de una sociedad. Es conjunto de ideas y valores que comprende, “... conocimiento, arte, creencias, moral, ética, leyes, usos y otras capacidades y usanzas adquiridas por el hombre en cuanto que es miembro de una sociedad" (Taylor, 1971). La cultura, como un proceso general, lleva a pensar que todo aquello que el hombre es o hace, y que no tiene su origen en la herencia biológica, quedaría englobado dentro del campo de la cultura. (Giner, 1979, págs. 73-97).

Al encontrarnos con diferentes culturas, podemos asegurar que estas son el resultado de las diferentes maneras que tiene el hombre de organizarse o de dar respuestas a problemas similares (Mira, Juan, 1984, pág. 131.) $)^{\text {ii }}$

Las diferentes culturas darán lugar a diferentes formas de comunicación. Dependiendo del poder de transmisión de los medios de comunicación de las distintas 
culturas, existirá fagocitación de unas culturas con respecto a otras. Algunas subculturas no se dejan arrastrar por las culturas mayoritarias. De esta manera, los medios de comunicación funcionan como elemento diferenciador o reivindicativo.

La cultura puede ser un elemento liberalizador de los pueblos, por lo que, desde diferentes ámbitos, se ha definido la función de la cultura y los medios de comunicación como transmisores de ésta. La UNESCO, desde 1970, ha celebrado diferentes conferencias en las que se han estudiado estos conceptos.

"Los medios de comunicación se concentran en unos pocos países, y la mayoría de los países se encuentran recluidos al estado de receptores pasivos de la información, que es difundida desde unos pocos centros (Discurso inaugural. Indira Ghandi).

Meses más tarde, se celebraba la conferencia de San José de Costa Rica. En esta reunión se volvía a insistir en dos ideas, por un lado el derecho que tiene todo individuo a utilizar los medios de comunicación como una herramienta cultural y, por otro, la responsabilidad que tienen los Estados para proporcionar este desarrollo cultural.

La televisión, como el medio de comunicación de masas por excelencia, se convierte así en un elemento fundamental para la mayoría de las culturas actuales. Sin embargo, la cultura es un proceso muy cambiante, que no se desarrolla en sí misma sino fruto del intercambio con otras cultu- ras. Por tanto, este cambio debe ser abierto, proporcionado y respetuoso.

En los comienzos de la televisión analógica, los estados europeos respaldaron la creación de televisiones públicas como el medio para dar a conocer su cultura. Estas televisiones generalistas tenían reservado un gran espacio para la información actualidad y objetividad-, la cultura y, en último lugar, el entretenimiento. Cuando en los años ochenta se produjo un aumento de los medios locales, se comprobó que una de las principales características de los informativos locales era la estrecha relación que mantenían con la audiencia. De esta manera, la objetividad se convertía en una referencia obligada, ya que, gran parte de las informaciones podían ser contrastadas por los espectadores.

Todos los investigadores de la comunicación local coinciden en asegurar que la demanda de información próxima se convierte en una de las principales causas de aparición de estos medios. La identificación con el medio de comunicación da lugar a grandes audiencias. Y del mismo modo que los medios locales conexionan con la audiencia, Internet conecta con sus usuarios, aportando información concreta sobre aspectos particulares. Lo que sería información a la carta. Al contrario que los medios generalistas que tienen que adaptarse a una mayoría.

A comienzos de los sesenta, Marshall Mc Lugan (1964) apuntaba que los llamados "nuevos medios" tienden a ofrecer conteni- 
dos basados en los medios existentes anteriormente. En este sentido, los primeros programas de radio eran obras de teatro dramatizadas, y la televisión, en sus comienzos, emitía espacios radiofónicos adaptados al formato televisivo. En la actualidad, cada servicio de la televisión interactiva prácticamente constituye una versión modificada de contenidos o programas ya existentes. Las películas bajo demanda, en esencia, son un servicio de alquiler de vídeo directamente desde el hogar. La mayoría de los canales de compra pueden considerarse una variante de los programas de telecompra lanzados en los noventa, o una versión televisiva de la compra por catálogo; y los juegos interactivos permiten que dos personas compitan desde diferentes lugares, en vez de hacerlo en la misma ubicación. Se trata de ampliaciones de programas o servicios atractivos para el público, pero no son radicalmente diferentes al modelo de televisión tradicional.

La televisión en España nace oficialmente el 28 de octubre de 1956. Pero hasta febrero de 1959, cuando se instala la red de repetidores en Barcelona, sólo puede ser recibida por los ciudadanos madrileños. Sin embargo, se produce un rapidísimo crecimiento de la televisión. La televisión se ha convertido en el mayor medio de comunicación que ha conocido la historia de la humanidad. Es decir, es un medio que satisface una demanda de ocio, que con independencia de estatuto cultural o económico, abarca prácticamente al conjunto de la sociedad, y es cubierto por otras formas de espectáculo y entretenimiento.

Nos atrevemos a decir que los visionarios de la televisión serían aquellos que han usado el medio escudriñando algunas de sus peculiaridades, como sistema de representación o, desde otra perspectiva, aquellos que han recorrido campos inéditos, y luego productos para la posterior evolución del medio.

Y, sin duda, la historia de la televisión en España posee algunas personalidades singulares que, con toda propiedad, pueden denominarse visionarias, como aquellos que previeron las funciones que desempeña la televisión en Internet. Es una forma híbrida que potenció al máximo las discontinuidades, la fragmentación, la apertura de diferentes segmentos de audiencia, la aceleración de la visión, el zapping convertido en una estrategia de lectura, y una valoración nueva del sonido, rara vez reconocida en las formas más ancestrales de la televisión. Estos visionarios eran profesionales como Iván Zulueta, que trabajaron en la televisión durante los sesenta. Actualmente, los que toman el relevo son los representantes de la televisión institucional en Internet, aquellos que desean llevar la cultura del español al mundo entero.

Con el nacimiento de Cervantes televisión se abre una nueva puerta para y por la cultura en español. Cervantes TV es la primera televisión cultural en español con cobertura mundial. La idea es transmitir noticias del ámbito cultural hispano, con 
especial énfasis en las actividades de los países en los cuales hay sedes del Instituto Cervantes. La página tiene varias secciones -la institución, lengua y enseñanza, música y danza, entrevistas, actividades de la sede, literatura y pensamiento, artes plásticas, informativos, etc.- con noticias actualizadas, así como una sección de documen- tales. También se imparten cursos de español directamente desde el portal, y en colaboración con Radio Televisión Española. Existe una emisión continua de programación que puede ser interrumpida por el usuario, seleccionando aquellos temas que desee consultar en ese momento.

\section{Conclusiones}

La televisión ha ido evolucionando hasta el punto de que algunos autores afirman que se ha producido su fallecimiento. Sin embargo, actualmente conviven tres modelos televisivos: el generalista, el modelo temático y el modelo convergente con Internet.

En los años noventa se consolida la interactividad como parte sustancial del nuevo modelo comunicativo, gracias todo ello al nacimiento y desarrollo de Internet, y a la expansión de los canales por satélite.

El satélite e Internet han decidido los nuevos usos de la televisión: ahora el espectador elige lo que ve, cómo y dónde desea. Internet posibilita la interactividad, y la televisión se convierte en contenido de Internet.

Aparecen nuevos conceptos en la sociedad comunicativa actual, como prosumers, que son los actores principales de la sociedad de la ubicuidad, cuyo lema es "anyone, anytime, anywhere.

Las Instituciones han canalizado los contenidos creados por los prosumers, y participan de la televisión en Internet. En el caso de España, una institución de prestigio como el Instituto Cervantes ha creado la primera televisión cultural para Internet, llevando la cultura en español por todo el mundo.

\section{Referencias}

AGUILERA, C. (1988): "Historia de la comunicación y de la prensa”, Atlas, Madrid.

ARANGUREN, J.L. (1986): "La comunicación humana", Tecnos, Madrid.

BELL, D. en MATTELART, A. (1993): "La comunicación mundo”, Fundesco, Madrid.
BRETON, Ph. y PROULX, S. (1990): "La explosión de la comunicación” Civilización, Badalona.

BUSTAMANTE, E. y ÁLVAREZ

MONZONCILLO, J.M. (1999): "Presente y futuro de la televisión digital”, Edipo, Madrid. 
CEBRIÁN HERREROS, M. (2001): "Modelos de televisión: generalista, temática y convergente con Internet”, Paidós, Barcelona.

COLOMBO, F. (1996):”Televisión, la realidad como espectáculo”, Gustavo Gili, Barcelona.

DEL CAMPO, S. (1984): “Tratado de sociología”, Taurus, Madrid.

ECO, U. (1968): “Apocalípticos e integrados”, Lumen, Barcelona.

GINER, S. (1972): "Sociedad de masas: crítica del pensamiento conservador”, Península, Barcelona.

GINER, S. (1979): “Sociología”, Península, Barcelona.

GÓNZALEZ BERBÉS, E. (1999): "Servicios interactivos para la televisión digital”,

JAMES, D. (1986): "Resolutions", L.A.C.E., Madrid.

JENSEN, K. B. (1993): "Metodologías cualitativas de investigación en comunicación de masas", Bosch Casa Editorial, Barcelona.
MONZÓN, C. (1987): "La opinión pública.

Teorías, conceptos y métodos”, Tecnos, Madrid.

MORAGAS, M. (1981): “Teorías de la

Comunicación”, Gustavo Gili, Barcelona.

PISCITELLI, A. (1993): "Post/televisión ecología de los medios en la era de Internet”, Paidós, Barcelona.

RAMONET, I. (2002): "La post-televisión Multimedia, Internet y globalización económica", Icaria, Barcelona.

SEWART, D.; KEEGAN, D. y HOLMBERG, B. (1983): "Distance education: International perspectives", Croom, Helm.

SWEDLOW, T (2000): "Interactive Enhanced Television: A Historical and Critical erspective", American Film Institute.

TAYLOR, E. B. (1971): "La ciencia de la cultura". En el concepto de cultura”, Anagrama, Barcelona.

\section{Notas}

${ }^{\text {i }}$ RODRÍGUEZ FUENTES, C. (2008): "Propaganda electoral en la red”. Congreso de periodismo digital. Huesca.

${ }^{i i}$ MIRA, J. F. en DEL CAMPO, S. (1984): Tratado de Sociología, Taurus, Madrid.

\section{Cita de este artículo}

Rodríguez Fuentes, C. (2010). Televisión en Internet. Revista Icono14 [en línea] 15 de Enero de 2010, № 15. pp. 114-132. Recuperado (Fecha de acceso), de http://www.icono14.net 